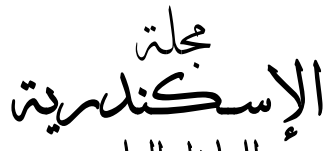 \\ للبناهل العلى
}

$r \cdot 1 r$

يوليو - سبتمبر

بحلد سب

\section{تأثير تناول الحبة السوداء وعسل النحل على الحالة الصحية للمصابات بسرطان الثدي}

$$
\text { حسن عبد الرعوف الهندي' ، محمد شريف أحمد عسكر '، وسوزان عبد الرحمن أبو شال' }
$$

المقدمسـة والمشكلة البحثية

السرطان هوبحموعه من الأمراض(أكثر من . . أمرض) تتشابه

في بعض الخصائص فيما بينها، وقد سميت بالسرطان لأن الأوعية

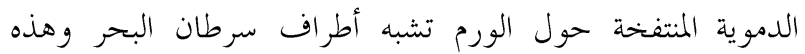

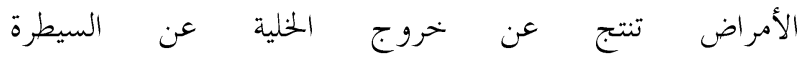
(Debasis and Preuss 2005). يعد مرض السرطان من المشاكل

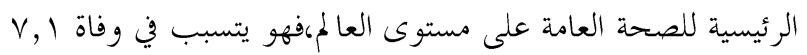
مليون فرد سنويا في مختلف أنحاء العالم. وقد تم التبؤ بأنه وبحلول

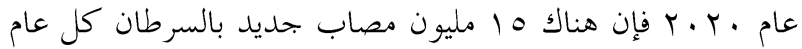

.(WHO. 2003)

وفي عام V . . r بلغت نسبة الإصابة بسرطان الثدي في المملكة

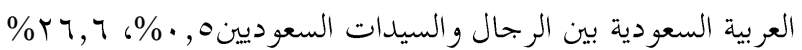
على التو الي من بحموع المصابين بالسرطان بكل الأنواع؛ و كان عدد

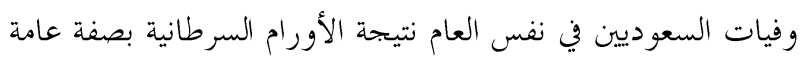

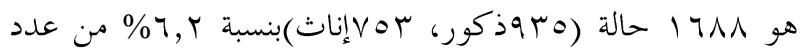

$$
\text { الوفيات الكلية بالمملكة(وزارة الصحة، ل . . r). }
$$

ويرتبط هذا الارتفاع في نسبة الإصابة بالمملكة العربية السعودية

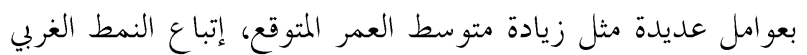

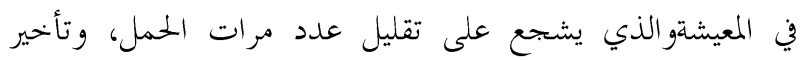

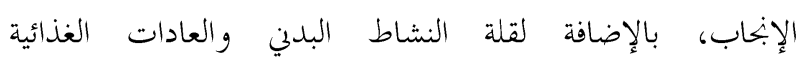

.(Ibrahim et al., 2008)

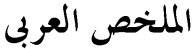

استهدفت هذه الدراسة التعرف على تأثير تناول كل من الحبة السوداء وعسل النحل على تحسين حالة المصابات بسرطان الثدي، أجريت الدراسة في قسم الأورام بمستشفى النور التخصصي وملينة

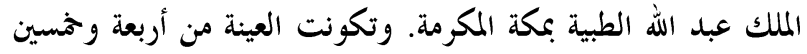

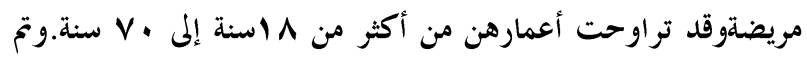

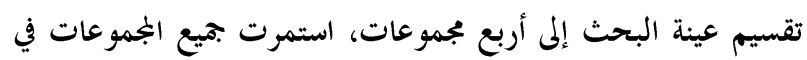

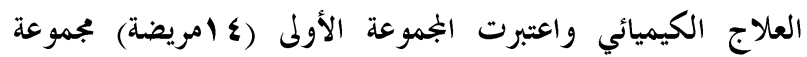

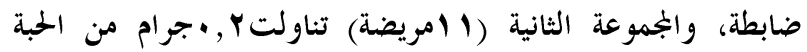
السوداء/كجم وزن الجسم خلال اليوم والجموعة الثالثة (ع المريضة)

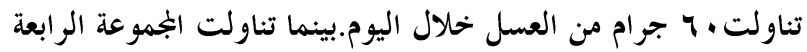

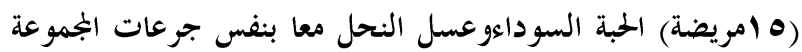

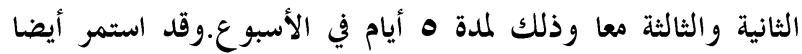

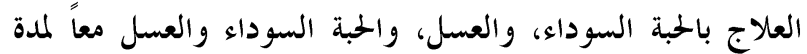
أسبوعين بعد انتهاء العلاج الكيميائي. تم استخدام الإستبانه كأداة لجممع بيانات البحث،حيث احتوت على عدة محاور وهي البيانات الشخصية، والمعلومات الصحية، وتقييم

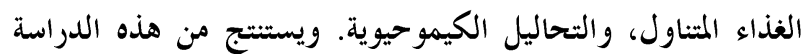

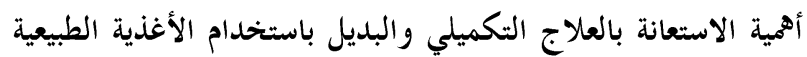
خاصة الحبة السوداء وعسل النحل للوقاية والحماية من مرض

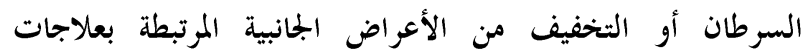

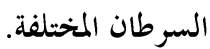

\footnotetext{
اكلية العلوم الطبية التطبيقية-جامعة أم القرى- مكة المكرمة- المملكة العربية السعودية

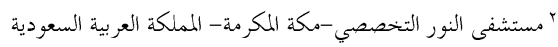

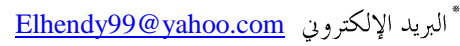

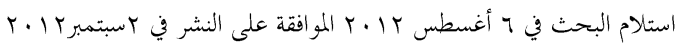




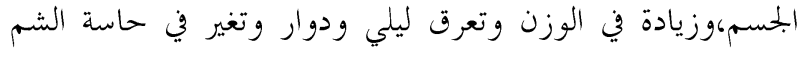

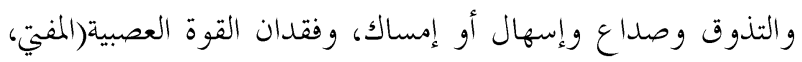

.(Brown, et al. 2003; Cancer Compass 2008; — ا I 1 个 أوضحت دراسة(2008) Alharbi, التى شملت · r امرأة مصابة

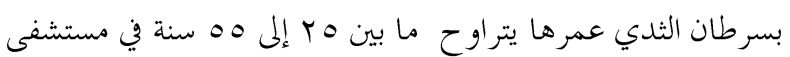

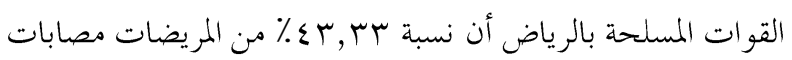

$$
\text { بفقر الدم (هيمو جلوبين اقل من ب ا جرام). }
$$

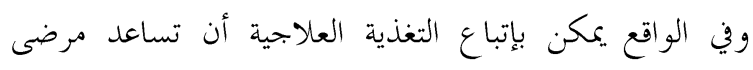

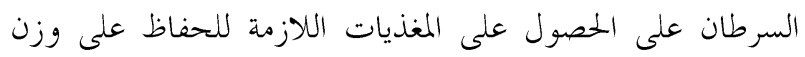

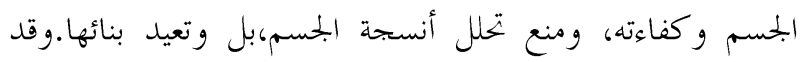

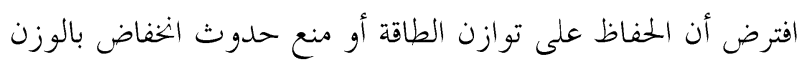
خلال علاج السرطان هو أهم الأهداف الغذائية للمرضى الناجين

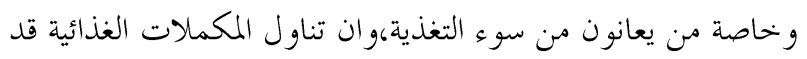
يساعد المرضى الذين لا يستطيعون تلبية احتياجاهم الغذائية

(Tian, et al. 2007) أوضحEdris (2009 أن الحبة السوداء هي إحدى الأنواع

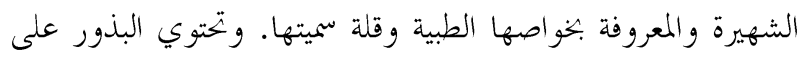

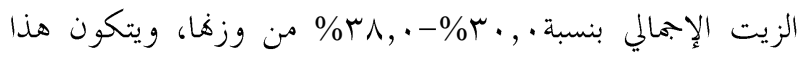

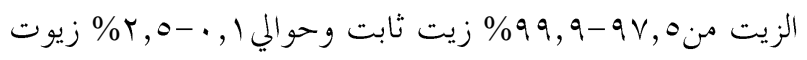

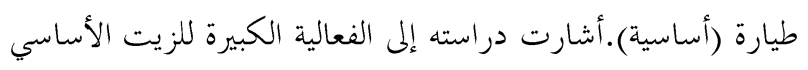
عندما يحقن مباشرة داخل الورمهفي تقليل حجم الورم، تثبيط انتشار

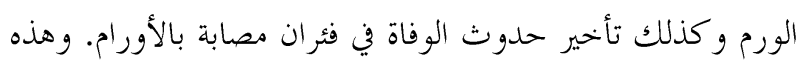

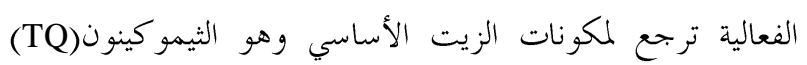

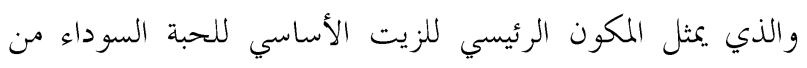
معظم المصادر.وقد تعزى هذه الفعالية لتأثيره المثبط لنمو الخنالايا السرطانية و كذلك قدرته على تحفيز الموت الخلوي المبرمج. درس(2010) تأثير الجمع بين العلاج بالأعشاب والعلاج الكيميائي التقليدي على نسبة حدوث الآتار الجانبية للعلاج الكيميائي في المريضات المصابات بالمرحلة الثانية لسرطان الثدي. فقد تم اختيار ، ع مصابة عشوائيا من النساء اللائي تتراوح أعمارهن

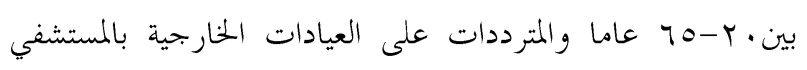

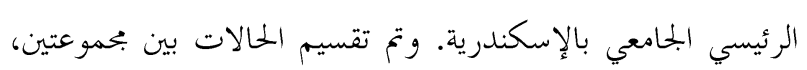

درس(2002) Mabrouk, et al. دور كل من الحبة السوداء وعسل النحل فن تثبيط السرطان المستحدث في فئران التجارب. حيث تم إعطاء بجموعتين من الفئران المصابة ب, •·جم حبة سوداء

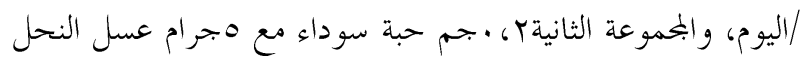

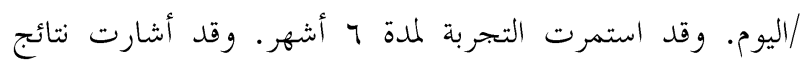

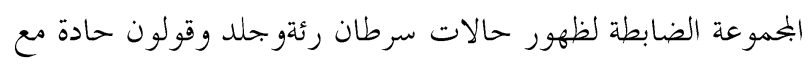

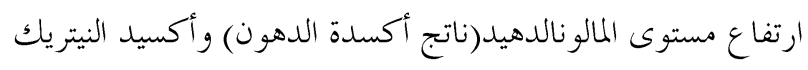

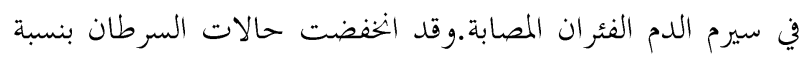
• م في الفئران التي تناولت الحبة السوداء. بينما اختفت تماما حالات السرطان بنسبة . . 1\% في بحموعة الفئران التي تم علاجها

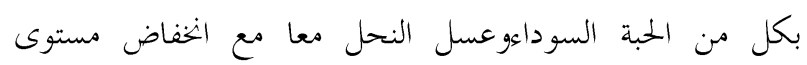
المالونالدهيد وأكسيد النيتريك في سيرم دم البمموعتين. أظهرت دراسة(2007) (Ait Mbarek, et al أن حقن مناطق

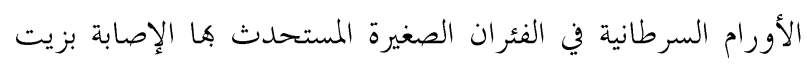
الحبة السوداء عددامرات خلالمیعساعة أدى إلى تثبيط تطور

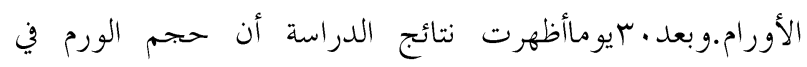

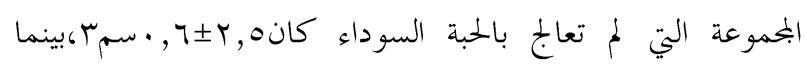

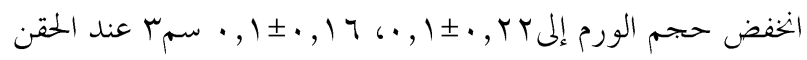

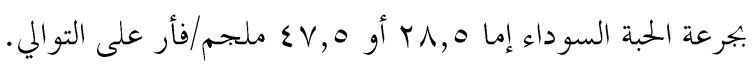
وتعاني العديد من حالات سرطان الثدي من فقر الدم، كأحد عواقب المرض نفسه أو علاجه. ويؤثر فقر الدم على نتائج العلاج،

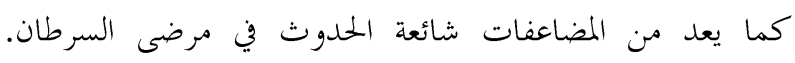
وضمن بيانات أخذت من ج؟ ؟ امرأة تلقين علاجا لسرطان الثدي، وجد أن فقر الدم خلال فترة استعمال العلاج الكيميائي المساعد

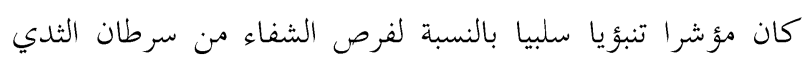

.(Boehm, et al. 2007)

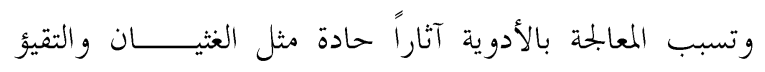

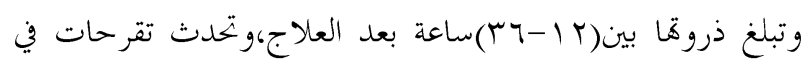

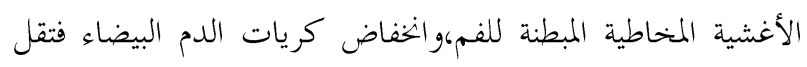
المقاومة للعدوى الجرثومية وكذلك حدوث الخفاض في الصفائح الدمويةِ فيؤدي إلى حدوث الترف الدموي، وكذلك هناك تأثيرات

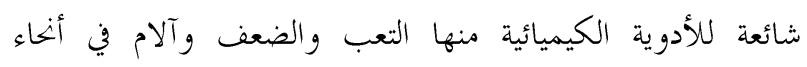


لذا هدف هذه الدراسة التعرف على مدى تأثير تناول كل من الخبة السوداء وعسل النحل على تحسين حالة المصابات بسرطان

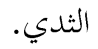

\section{المواد وطرق البحث}

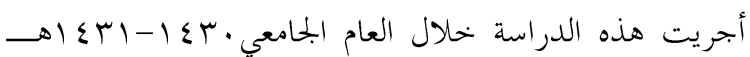

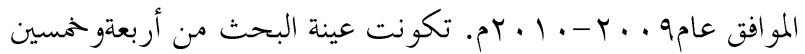
مريضة والمراجعات لقسم الأورام بمستشفى النور التخصصي ومدينة

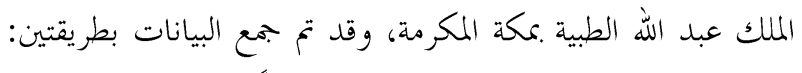

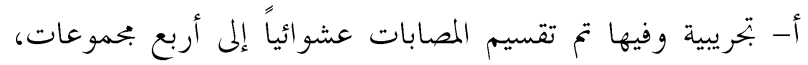

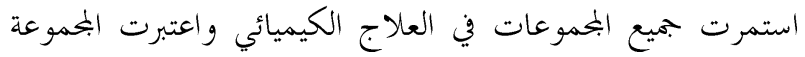
الأولى(ع ا مريضة)بحموعة ضابطة،والبحموعة الثانية (11 مريضة)

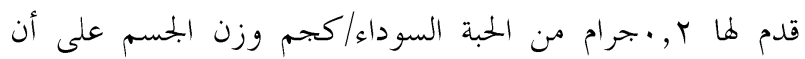
تقسم لثلاث كميات،تناولتها قبل الوجبات الثلاث الرئيسية خلال

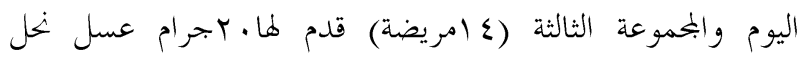
السدر(من مناحل النحل الجوال)قبل تناول كل وجبة من الوجبات

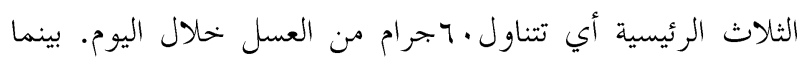

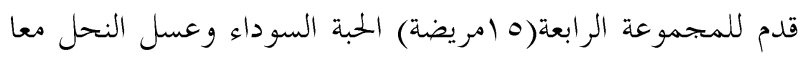
بنفس الجرعات التي تقدم للمجموعة الثانية والثالثة معاوذلك لمدة ألثاء ه أيام في الأسبوع. وقد استمر ذلك حتى انتهاء العلاج الكيميائي

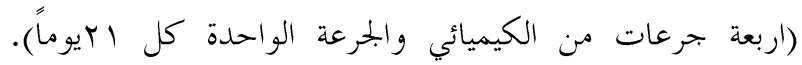

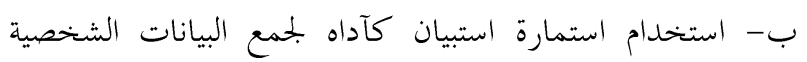
واحتوى الاستبيان عدة محاور وتضمن المحور الأول البيانات

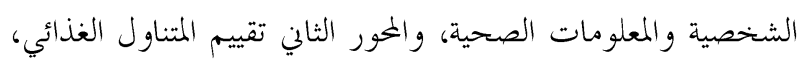

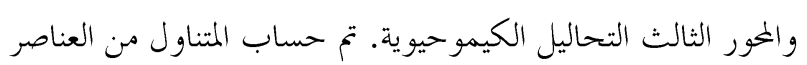
الغذائية وذلك عن طريق إدخال البيانات في البرنامج العربي لتحليل

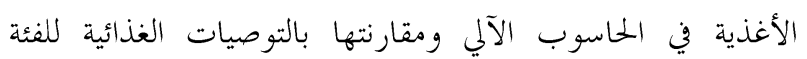

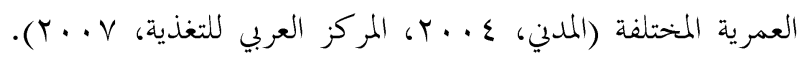

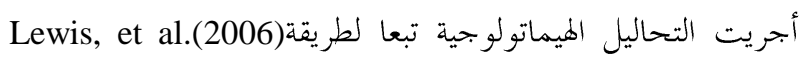

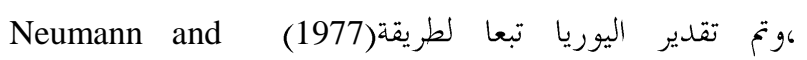
ZZiegenhovn Bartels, et al. (1972) بطريقة(1969)Trinder) استُخدِمت طريقة بيوريت لتقدير تركيز
الأولى للدراسة والثانية بجموعة ضابطة. تناولت بجموعة الدراسة

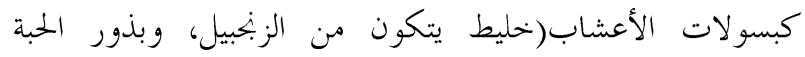
السوداءووالكر كم،وبذور الهيل،وحصا لبان(لبان دكر)بصفة منتظمة

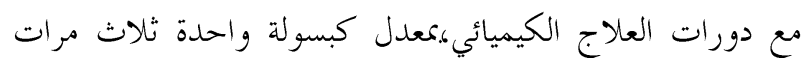

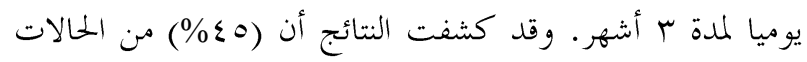

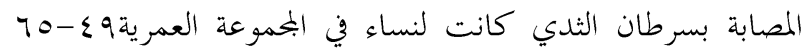

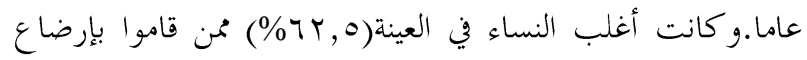

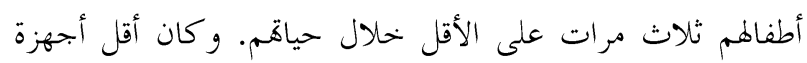

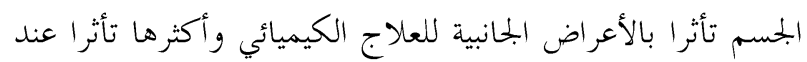
الجمع بين العلاج بالأعشاب والعلاج الكيميائي التقليدي هي: نتائج

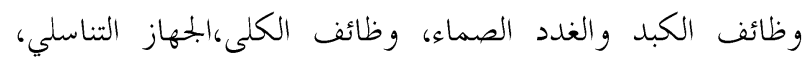

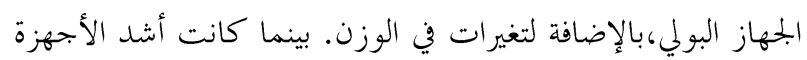

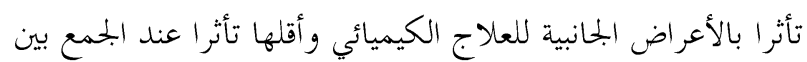

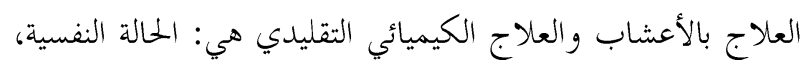

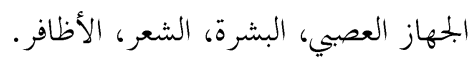
هدفت دراسة محمد وآخرون (1) السيدات المصابات بسرطان الثدي لكبسولات الحبة السوداء وردة

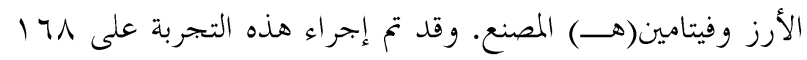

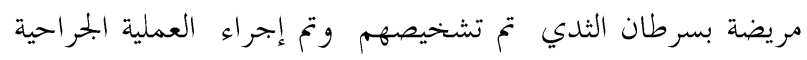
هم، ثم تم علاجهن بستة دورات من العلاج الكيميائي القياسي تمريم تبع ذلك علاجهن بالعلاج الإشعاعي ثم بعد ذلك تلك تم إعطائهن دواء

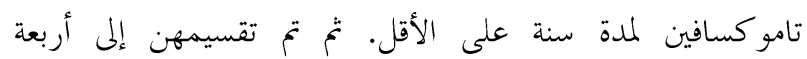

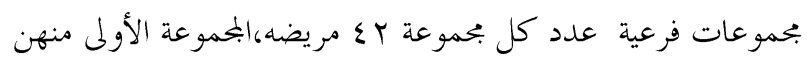
لم تتلقى أى علاج سوى العلاجات القياسية المقررة، أما باقي

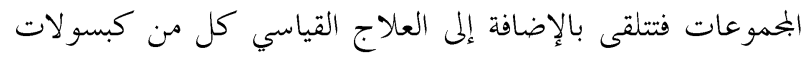

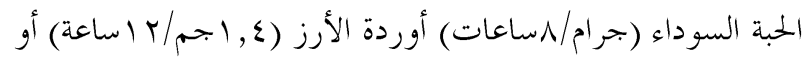

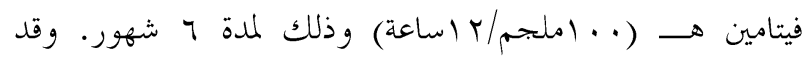

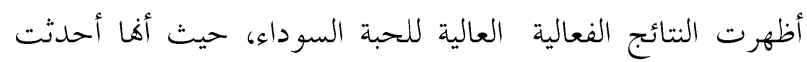
تحسنا واضح في مستويات جميع المقاييس الكيموحيوية التى تم

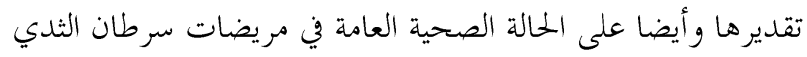
أكثر من كبسو لات ردة الأرز أوفيتامين هـ للذين يخضعون للعلاج الكيمائي والإشعاعي و كذلك التامو كسيفين. 
مع المرأة التي تلقت قدرا أقل من التعليم.وفي الوقت نفسه، فإن نسب النجاة والبقاء في مختلف أنواع السرطان ترتفع لدى النساء

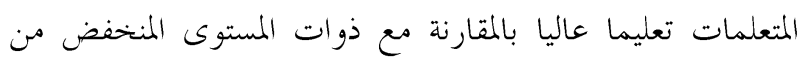

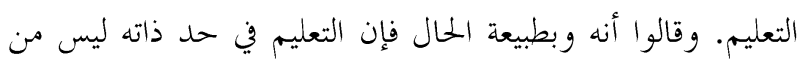

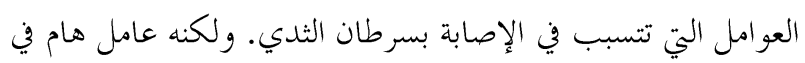

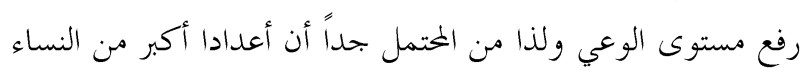

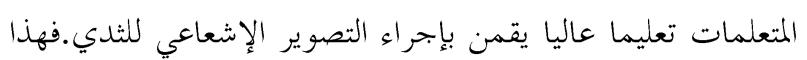

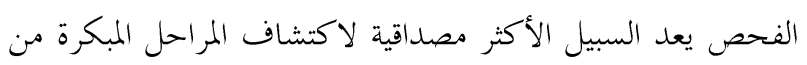

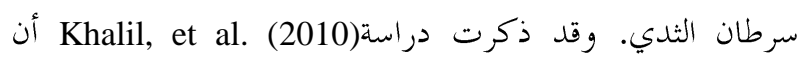
\&\% من المريضات المصابات بالمرحلة الثانية لسرطان الثدي في

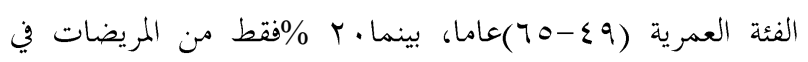

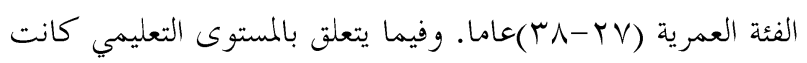

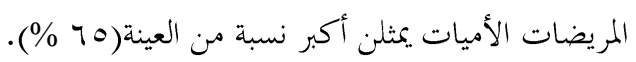
وبالنسبة لكتلة الجمسم فقد أظهرت نتائج الدراسة(جدول (أن نسبة 9 \% \% م مصابات بالسمنة بدرجاها المختلفة سواء بالبدانة

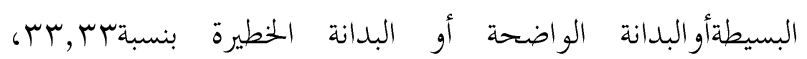

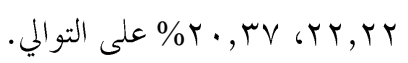
وقد قدم(2007) Campbell,et al. عدد من الأسباب التي يعتقد أهاوراء اكتساب الوزن المرتبط باستعمال العلاج الكيميائي في

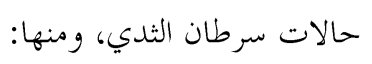

البروتين الكلى؛تبعاً لـWeichselbaum لتقدير البليروبين.تم تحليل البيانات باستخدام

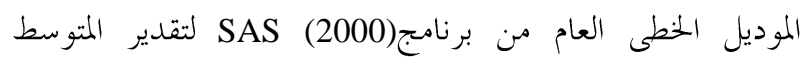

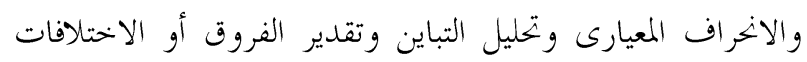

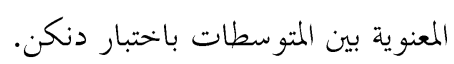

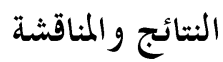

يشير جدول(1) للبيانات العامةوالمعلومات الصحية للسيدات

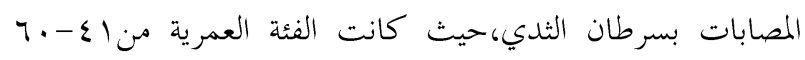

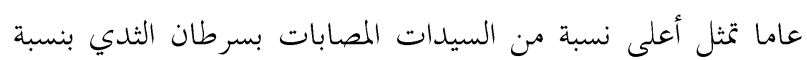
.\%VT, rr

وتتفق نتائج هذه الدراسة مع ما أعلنته American Cancer فقد أفادت أن حوالي ·ـ Society (2008) سرطان الثدي في النساء تحدث بعد سن الخمسين. تنوع مستوى التعليم(جدول ()بين عينة السيدات المصابات

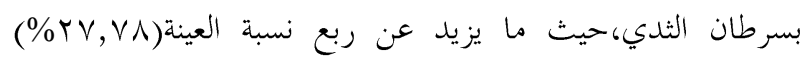

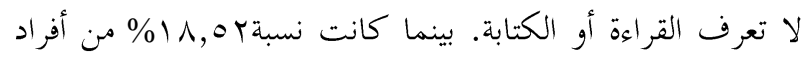
العينة حاصلات على درجات جامعية أو أعلى.

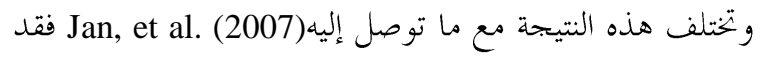
ذكرا أن المرأة التي تنال قدرا وافرا من التعليم تكون أكثر عرضة إلته

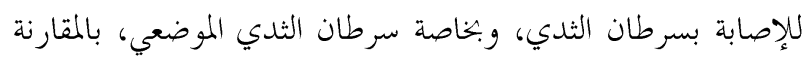

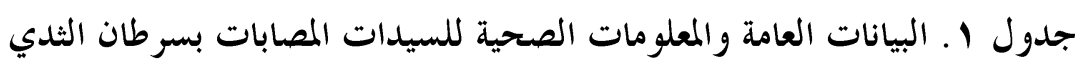

\begin{tabular}{|c|c|c|c|c|c|}
\hline$\%$ & العدد العد & البيان & $\%$ & العدد العد & البيان \\
\hline \multicolumn{5}{|c|}{ كتلة الجسمم } & العمر (عام) \\
\hline r.V. & r & نحيف & $11_{699}$ & v & $\varepsilon .-\mu$. \\
\hline$T \cdot 6 r V$ & 11 & مالئم & Y967T & 17 & $0 .-\varepsilon 1$ \\
\hline سח، & 11 & بدانة بسيطة & $\sum r_{609}$ & r & $7 .-01$ \\
\hline TYGT & ir & بدانة واضحة & $\mid \varepsilon(\lambda \mid$ & $\wedge$ & . ب عاما فأكثر. \\
\hline$t \cdot g r v$ & 11 & بدانة خطيرة & $1 \cdots 6$ & $0 \varepsilon$ & البمموع \\
\hline $1 \ldots 6$ & $0 \varepsilon$ & \multicolumn{3}{|l|}{ البحمو ع } & \\
\hline \multicolumn{2}{|c|}{ المتوسط 玉الانحر اف المعياري } & البيان للعينة ككل & & & مستوى التعليم \\
\hline \multicolumn{2}{|c|}{ IYGKY $\pm \lambda r_{6} Y \Lambda$} & النبض (نبضة/دقيقة) & TV.VA & 10 & أمية \\
\hline \multicolumn{2}{|c|}{$11601 \pm 1 \% 0 / V \mu$} & ضغط الدم (ملم/زئبق) & 17678 & 9 & تقر أ و تكتب \\
\hline \multicolumn{2}{|c|}{$V .97 \pm r 967 r$} & سمك الجلد ا بلد & $11_{6} 0 \mathrm{Y}$ & 1. & شهادة ابتدائية \\
\hline \multirow{4}{*}{\multicolumn{2}{|c|}{$r r_{6} \varepsilon V \pm 99697$}} & محيط البطن (سم) & r.V. & r & شهادة متو سطة \\
\hline & & & $1 \leqslant 6 \wedge \mid$ & $\wedge$ & شهادة ثانوية \\
\hline & & & $11160 \mathrm{Y}$ & 1. & شهادة جامعية وأعلى \\
\hline & & & $1 \ldots 6$ & $0 \varepsilon$ & البحمو ع \\
\hline
\end{tabular}


للسيدات المصابات بسرطان الثدي. على العكس فقد ارتفع المتناول من البروتين،والدهون، الكربوهيدرات، الحديد، الفوسفور. استنتج (2006) وجود صلة مباشرة بين خطر الإصابة بسرطان الثدي وتناول الأطعمة التي تؤدي لزيادة الأنسولين.

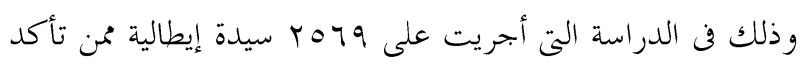

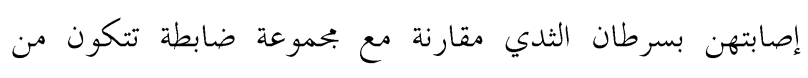

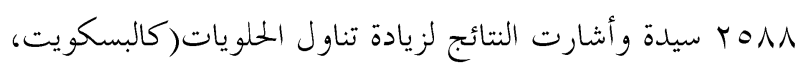
و المخبوزات كالبريوش، الكعكات، والآيس كريم) والسكريات

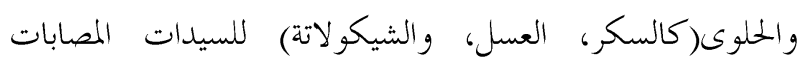
بسرطان الثدي مقارنة بالبمموعة الضابطة.

وقد أوضحت دراسة(2007) Thiébaut et al., أن النساء في مرحلة ما بعد انقطاع الطمث اللاتي بلغ متوسط استهلاكهن

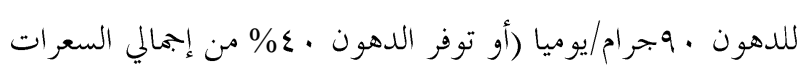

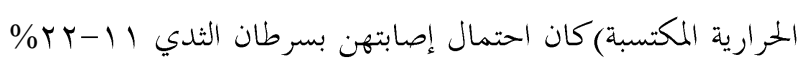

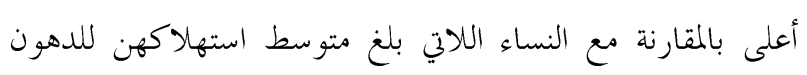

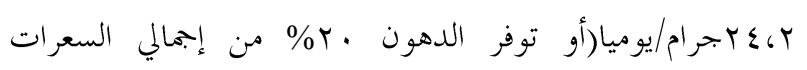

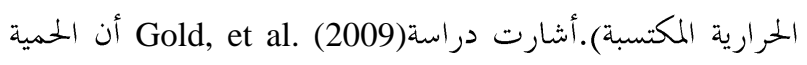
التي تحتوي على كميات أكبر من الخضر و الفواكه والألياف،وتقل

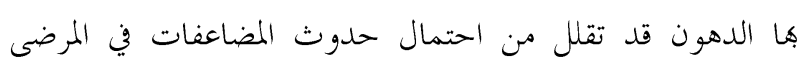
الناجين من سرطان الثدي.
نوعية العلاج الكيميائي، طول فترة العلاج، الإرهاق، قلة

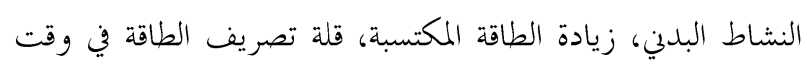

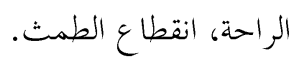

و بالنسبة للمعلومات الصحية و التاريخ المرضي للسيدات المصابات بسرطان الثدي فيظهر جدول(1) أنه كان متوسطات

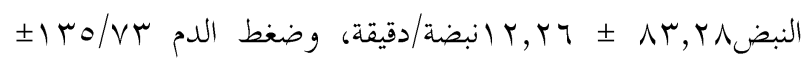
1,01 املم/زئبق، وسمك الجللدr,

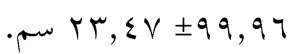
وأشار Nagi, et al. (2008) إلى أن، بذور الحبة السوداء فعالة في الحماية من ارتفاع ضغط الدم ربما من خلال نشال نشاطها المضادة

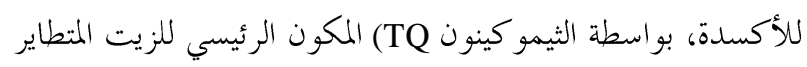
المستخرج من بذور الحبة السوداء. يوضح جدول(r) مقارنة المتناول من العناصر الغذائية خلال

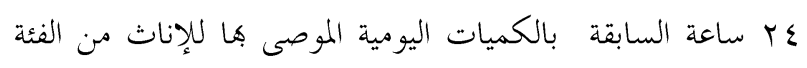
العمرية .ب-V V عاما. وقد ظهر أن استهلاك الطاقة للسيدات

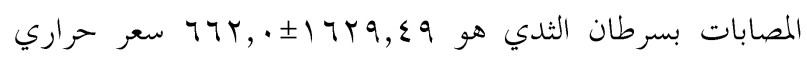

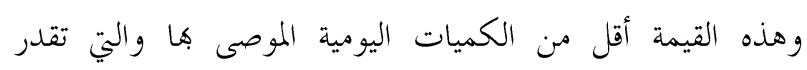

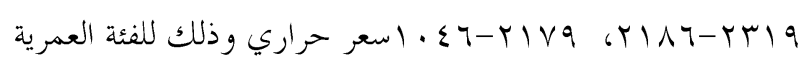

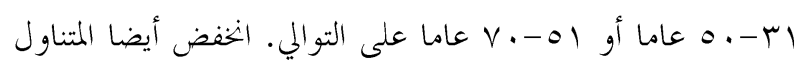

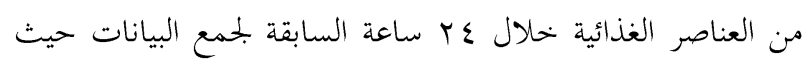

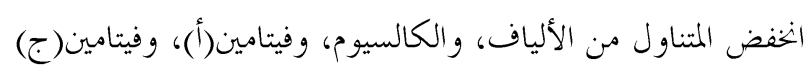

جدول Y. مقارنة المتناول من العناصر الغذائية بالكميات اليومية الموصى بها للإناث

\begin{tabular}{|c|c|c|c|}
\hline الكميات المتناولة & \multicolumn{2}{|c|}{ الكميات اليومية الموصى بها (المدني، ع · + †) } & \multirow{3}{*}{ الطاقة (سعر حراري) العنصر الغذائي } \\
\hline $7 \pi r, \cdot \pm 17 r 9, \varepsilon 9$ & Vl & آ- إ-0 سنة & \\
\hline & $Y \cdot\{Y-Y \mid \vee q$ & $Y \backslash \Lambda T-Y M \backslash 9$ & \\
\hline$r \tau, \neg r \pm V r, q$. & \multicolumn{2}{|c|}{$\varepsilon\rceil$} & البروتين (جرام) \\
\hline$r r, 1 r \pm 7 r, \cdot r$ & \multicolumn{2}{|c|}{$00-0}$. & الدهون (جرام) \\
\hline $19,11 \pm 19 \varepsilon, 94$ & \multicolumn{2}{|c|}{$1 \pi}$. & الكر بوهيدر ات (جرام) \\
\hline $7, r V \pm 11,0 r$ & \multicolumn{2}{|c|}{ ro } & الألياف (جرام) \\
\hline $\mid r, r r \pm r \cdot, 11$ & \multicolumn{2}{|c|}{11} & الحديد (مليجرام) \\
\hline$r r \cdot, r V \pm 0 T 9, \wedge V$ & \multicolumn{2}{|c|}{$1 \ldots$} & الكالسيوم (مليجرام) \\
\hline$\varepsilon .9,01 \pm 991,0 \%$ & \multicolumn{2}{|c|}{$\vee \cdots$} & الفوسفور (مليجرام) \\
\hline$r q 9, \cdot \varepsilon \pm 01 r, \vee$. & \multicolumn{2}{|c|}{$\mathrm{V} \cdot$} & فيتامين (أ) (ميكروجرام) \\
\hline$r_{1, \tau \wedge} \pm r_{0}, v_{1}$ & \multicolumn{2}{|c|}{ vo } & فيتامين (ج) (مليجرام) \\
\hline
\end{tabular}




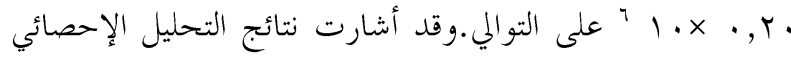

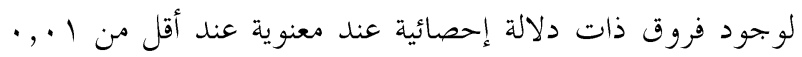
بين المحموعة الضابطة من جهة والمحموعات التجريبة من جهة أخرى. (n)

انخفضت أيضا نسبة الهيماتوكريت(جدولع)فن المحموعة الضابطة مقارنة بكل من المستوى الطبيعي والمجموعات العلاجية

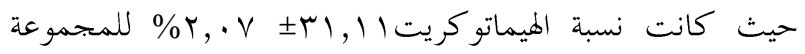

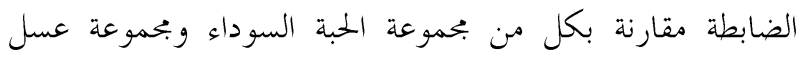
النحل وبحموعة الحبة السوداء وعسل النحل حيث كانت النسبة

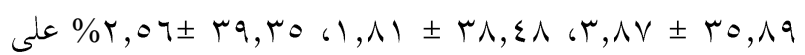
الترتيب. وأظهرت نتائج التحليل الإحصائي لوجود فروق معنوية(مستوى دلالة أقل ( •. • ).
بالنسبة لصورة الدم يتضح من النتائج جدول (T) أن مستوى الهيموجلوبين قبل العلاج كان منخفضا مقارنة بالمستوى الطبيعي(r,0 بسرطان الثدي.وقد ارتفع مستوى الهيموجلوبين أثناء العلاج للمجموعات التجريبية وكان ضمن حدود المستوى الطبيعي مقارنة بالمجموعة الضابطة. وقد استمر مستوى الهيموجلوبين طبيعيا حتى بعد انتهاء العلاج بأسبوعين. يشير جدول(ع)لنتائج تحليل الدم للمجموعة الضابطة

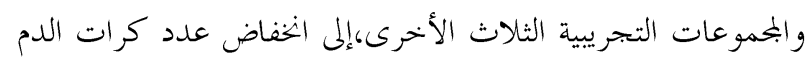

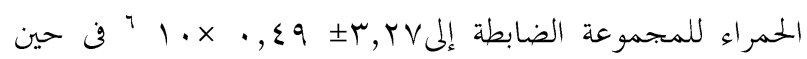

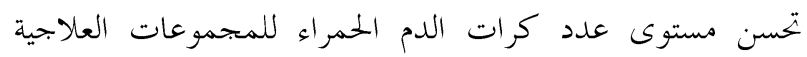
الثلاث التي تناولت الخبة السوداء وعسل النحل والحبة السوداء وعسل النحل معا إلى • ع,

جدول س. مستتى الميموجلوبين للمجموعة الضابطة والجمموعات التجريبية قبل وأثناء وبعد العلاج

\begin{tabular}{|c|c|c|c|}
\hline بعد العلاج بأسبوعين ** & أثناء العلاج* & قبل العلاج ** & الهيمو جلوبين \\
\hline & L).../ $1 V-1 Y, 0$ & & المستوى الطبيعى \\
\hline r., $74 \pm 9, \vee q$ & $\tau \cdot, \wedge \cdot \pm q, \vee r$ & $\cdot, 0 r \pm q, v \varepsilon$ & البمموعة الضابطة \\
\hline$\cdot, \vee \wedge \wedge \pm 1 r, 9 \varepsilon$ & $-1,1 r \pm 1 r, 10$ & $\cdot, \wedge 0 \pm 9, \vee 1$ & بجموعة الحبة السوداء \\
\hline$\cdot, \pi r \pm 1 r, q$. & $\cdot, V \wedge \pm 1 Y, \circ V$ & ${ }^{i} \cdot, \vee \vee \pm 1 \cdot, \vee 0$ & مجموعة عسل النحل \\
\hline$i \cdot, \vee \neg \pm 1\{, r q$ & $\cdot, \pi r \pm 1 r, .0$ & $\cdot, 9 \wedge \pm 1 \cdot, \vee \vee \varepsilon$ & بحموعة الحبة السوداء + عسل النحل \\
\hline
\end{tabular}

جدول ع ـ المقاييس الهيماتولوجية للمجموعة الضابطة والجمموعات التجريبية

\begin{tabular}{|c|c|c|c|c|c|}
\hline + مجموعة الحبة السوداء & جمموعة عسل النحل & السموعة الحبة & البجموعة الضابطة & المستوى الطبيعي & \\
\hline I., $, \pm \varepsilon, 7 \varepsilon$ & '.,Yד $\pm \varepsilon, 01$ & $\cdot, 7\rceil \pm \varepsilon, \varepsilon$. & $\because, \Sigma q \pm r, r V$ & $1 . \times 760-\varepsilon 60$ & عدد كرات الدم الحمر اء \\
\hline$r, 0 r \pm r_{q, r_{0}}$ & $\{, \wedge 1 \pm \mu \wedge, \Sigma \wedge$ & $r, \wedge \vee \pm r_{0, \wedge q}$ & $e_{r}, v \pm r 1,11$ & $\% \varepsilon v-r y$ & الهيماتو كريت \\
\hline$\varepsilon r, q \pm r 00, \varepsilon$ & $\Lambda \cdot, 1 \pm r \vee \tau, \Lambda$ & $q \vee, r \pm r q \wedge, 1$ & $9 r, 1 \pm r \wedge \neg, 1$ & $\varepsilon \cdots-10$ & صفائح دموية \\
\hline${ }^{i}, r \cdot \pm \cdot V, r T$ & $1, \Sigma q \pm \vee, r \wedge$ & $1,9 v \pm v, .9$ & $r, r y \pm 0,1 r$ & $r^{r} 1 . \times 11-r 69$ & عدد كرات الدم البيضاء \\
\hline & & & & \multicolumn{2}{|c|}{ العد التفريقى لكر ات الدم البيضاء } \\
\hline$\cdot, 9 \cdot \pm 1, \wedge \wedge$ & $1,0 \cdot \pm 1, \wedge \wedge$ & $\cdot, \vee 9 \pm 1,9 \leq$ & $\cdot,\{0 \pm r, 91$ & صفر - ص ا ص & إيزونوفيل \\
\hline$\Lambda, T V \pm r r, V \wedge$ & $0,1 r \pm \mu r, \lambda \Lambda$ & $1 ., 07 \pm r \varepsilon, 09$ & $1 \varepsilon, \vee q \pm r \wedge, \vee_{0}$ & $\% \varepsilon 0-r$. & ليمفو سيت \\
\hline $1, \wedge 0 \pm \wedge, \cdot \varepsilon$ & $r, r \pm \wedge, r \mid$ & $\varepsilon, \varepsilon \pm q, r_{1}$ & $7,1 Y \pm 1 \cdot, \cdot 7$ & $\% 1 \cdot-r$ & مونوسيت \\
\hline$\wedge, 9 \wedge \pm 09, \wedge 9$ & $\varphi, V, \Sigma 0 \pm 0 \leqslant, .0$ & $\varphi_{\wedge, \wedge \top \pm \Sigma \vee, \vee \vee}$ & $-10, v \mu \pm \varepsilon 9,11$ & \% & نتروفيل * \\
\hline$\because, 19 \pm \cdot, r_{\Lambda}$ & I., ${ }^{\prime} q_{q \pm} \pm, \Sigma \varepsilon$ & i., $\leq \varepsilon \pm \cdot, v 1$ & '., $\Sigma 0 \pm \cdot, \vee r$ & صفر - صr & بازوفيل \\
\hline
\end{tabular}


أوضح الحقيل(T · T. T) أن العلاج الكيميائي يسبب ضعف الجهاز المناعي للجسم وبالتالي تزداد خطورة الإصابة بالعدوى،

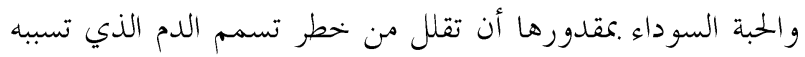

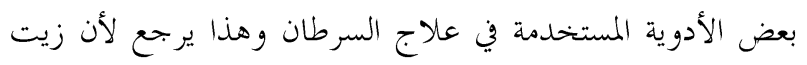

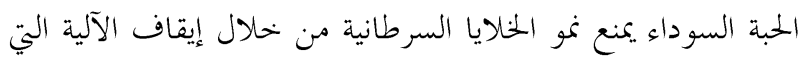
تسمح بتطور الأوعية الدموية داخل الورم السرطاني وبتالي غياب

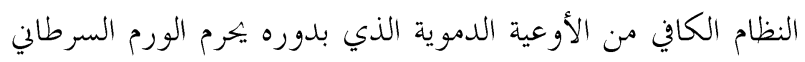

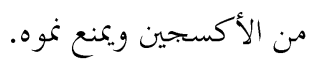
و لم تتفق نتائج هذه الدراسة مع دراسة(2010) التى Islam,

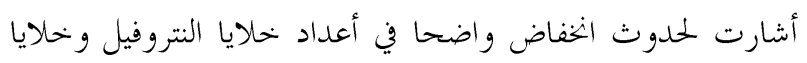

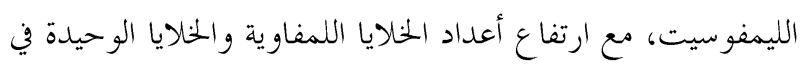
بحرى الدم في بحموعة الجرذان التي تناولت الحبة السوداء. يشير جدول(0)لارتفاع مستوى اليوريا في سيرم الدم للسيدات

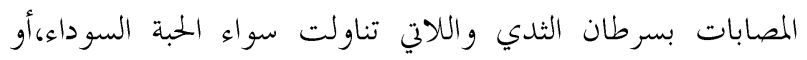
عسل النحل،أو الحبة السوداء وعسل النحل معا وذلك مقارنة

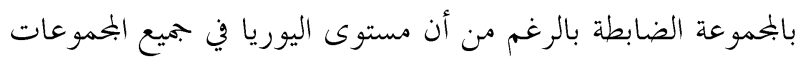

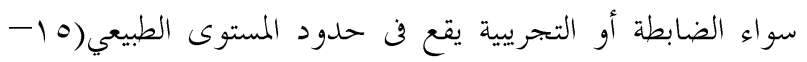

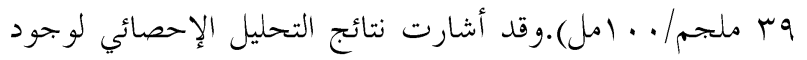

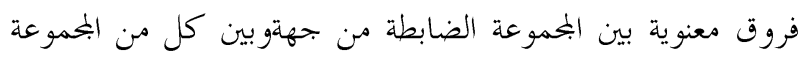

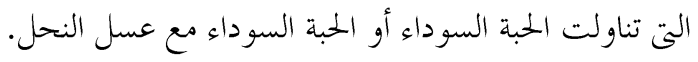
ارتفعت أيضا مستويات الكرياتينين في سيرم الدم للسيدات المصابات بسرطان الثدي واللاتي تناولت سواء الحبة السوداءءأو عسل النحل، أو الحبة السوداء وعسل النحل معاوذلك مقارنة

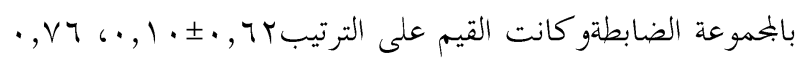
. كانت هناك فروق معنوية(مستوى احتمالية أقل من ا +, · ) بين

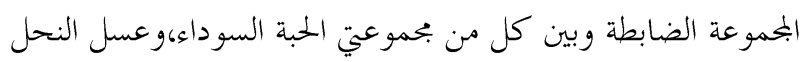
(جدول 0) (جمول) ارتفع مستوى الجلو كوز في البحموعة الضابطة والبحموعة الــلاتي

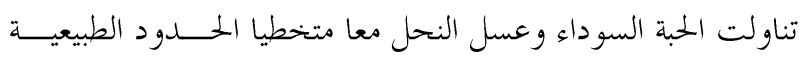

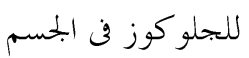

لم يحدث تغيير في قيم الصفائح الدموية في المجموعات التجريية

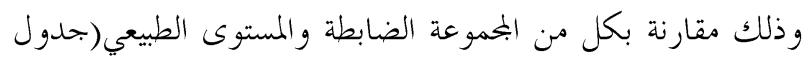

ويلعب فقر الدم دورا كبيرا في العجز الوظيفي الذي غالبا ما

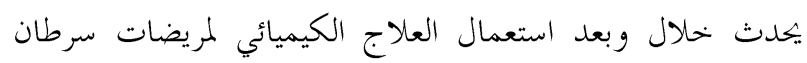

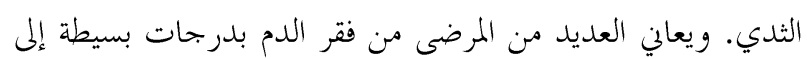
متوسطة،بحيث لا تستدعي نقل الدم. ولكن فقر الدم قد يؤثر سلبا فريا

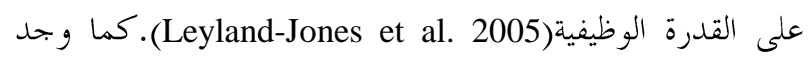
أنه من بين 0 Gianni et al (2008) الثدي وتلقت علاجا كيميائيا مساعدا، سجلت الإصابة بفقر الدم لهابن في الا \% من الحالات خلال فترة العلاج الكيميائي المساعد. أوضحت دراسة Alharbi (2008) التئ أجريت على · ب امرأة مصابة بسرطان الثدي في مستشفى القوات المسلحة أن نسبة

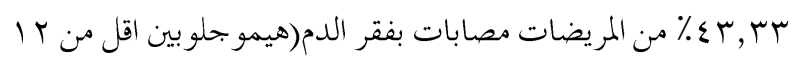
جرام).ويتضح من ذلك أن فقر الدم ينتشر بنسبة كبيرة بين المصابات بسرطان الثدي ولكن أظهرت نتائج هذه الدراسة أن الحبة بندية

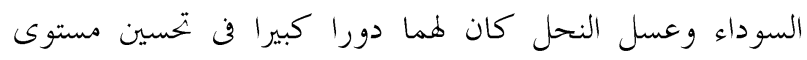

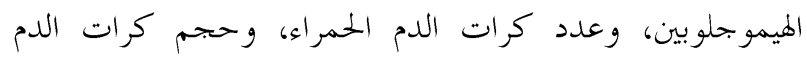

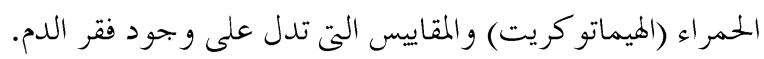
انخفض عدد كرات الدم البيضاء في البحموعة الضابطة معنويا (احتمالية اقل من ه •، .) مقارنة بالمحموعات التئ تناولت الحبة

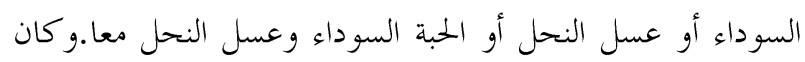
عدد كرات الدم البيضاء r

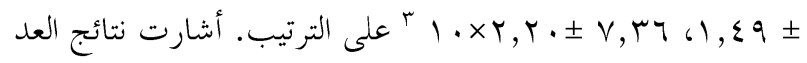

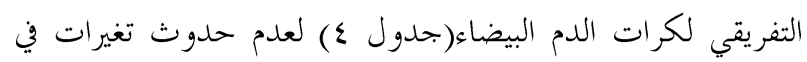
قيم كل من خلايا إيزونوفيل، وليمفوسيت، ومونوسيت فن كل من

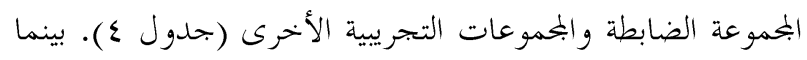

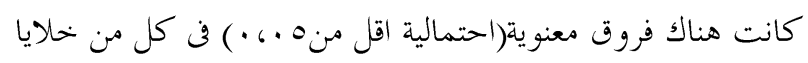

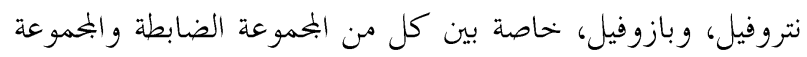
التي تناولت الحبة السوداء من جهة وبين البحموعة التئ تناولت الحبة

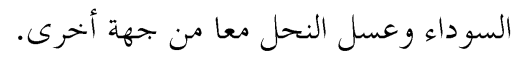


جدول ه. وظائف الكلى والجلو كوز ووظائف الكبد للمجموعة الضابطة والجموعات التجريبية

\begin{tabular}{|c|c|c|c|c|c|}
\hline + مجموعلة الحبة السوداء & مجموعة عسل النحل & مجموعة الحبة السوداء & البموعة الضابطة & المستوى الطبيعي & \\
\hline & & & & \multicolumn{2}{|c|}{ وظائف الكلى والجلو كوز } \\
\hline$\{, .0 \pm r q, 1)$ & $\varphi_{i r,}, \Lambda \pm r_{0}, .0$ & $V, 19 \pm r v, \Sigma r$ & $-q, 7 \pm 19, \wedge r$ & $r_{q}-10$ & ملجمي/. . 1 مل \\
\hline$-\tau^{\prime} \cdot, \cdot V \pm \cdot, V r$ & $\cdot, 1 r \pm \cdot, v \wedge$ & $\cdot, \mid \vee \pm \cdot, \vee\urcorner$ & $\cdot, 1 \cdot \pm \cdot, \pi r$ & $1, r-., 7$ & 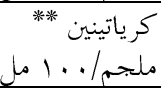 \\
\hline \multirow[t]{2}{*}{$r_{\Lambda, 0 \pm 1 r_{0}, \Sigma}$} & $-r, 1 \pm 1 \cdot r, r$ & $r_{q}, \pm 117, \varepsilon$ & $\Lambda 1, r \pm 1 V r, 1$ & $110-v$ & ملجم/ . .. ا مل \\
\hline & & & & & وظائف الكبد \\
\hline$\cdot, ., r \pm V, r V$ & $\cdot, T T \pm V, r \varepsilon$ & $\cdot, \wedge \circ \pm V, Y_{q}$ & $\because, 9 \wedge \pm \neg, \Gamma \wedge$ & $\lambda, r-\urcorner, \lambda$ & 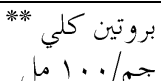 \\
\hline$\cdot, r \leq \pm r, 7 q$ & $\cdot, r Y \pm r, V$. & $\{, \varepsilon \cdot \pm r, 0 \varepsilon$ & $\cdot, v) \pm r, 1$. & $0-r, \varepsilon$ & ألبومين ... 1 مل \\
\hline$\cdot, \wedge \pm \cdot, \varepsilon 1$ & $1,1 \leqslant \pm \cdot, \varepsilon \wedge$ & $\cdot, r \circ \pm \cdot, \varepsilon$. & $\cdot, r \pm \pm \cdot, r \varepsilon$ & صفر - r, & بليرو بين \\
\hline
\end{tabular}

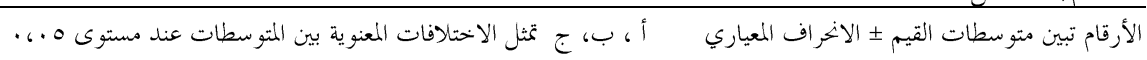

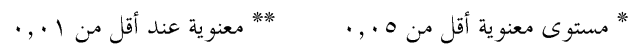

خلال تحفيز النشاط البلعمي في الخلايا البالعة الكبيرة إما بصورة مباشرة أو من خلال تنشيط الخلايا اللمفاوية.

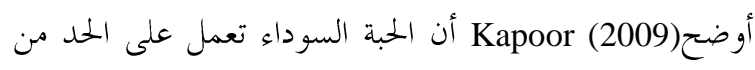
تلف الحمض النووي DNA وبالتالي تمنع بداية تكوين السرطان في

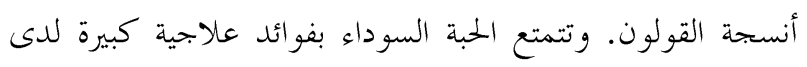

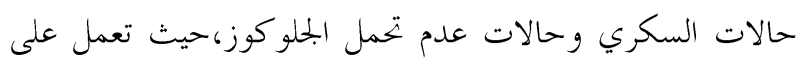

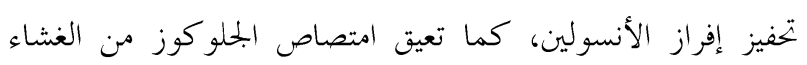
المخاطي للأمعاء.

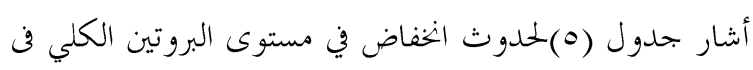
البحموعة الضابطة مقارنة بالمستويات الطبيعية للبروتين الكلي في فئول

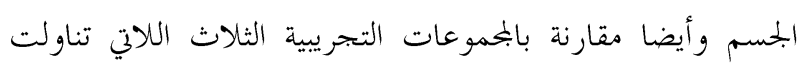

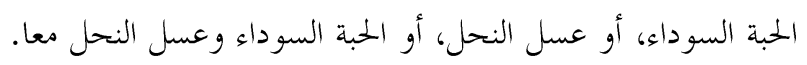

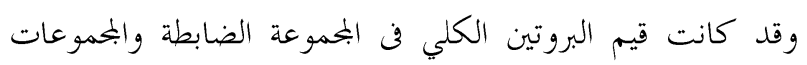

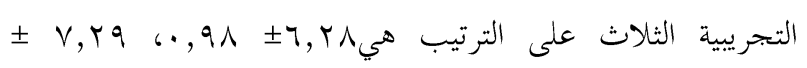

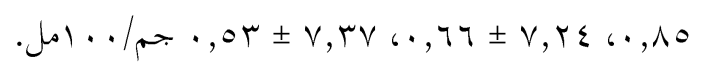
تشاهت مستويات الألبومين تماما مع مستويات البروتين الكلي،

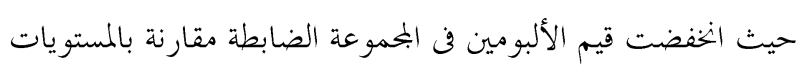

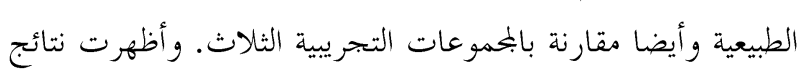

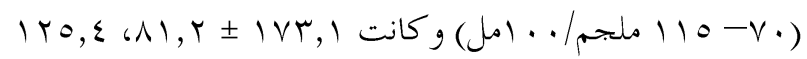
I

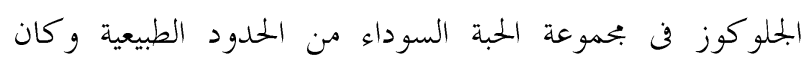

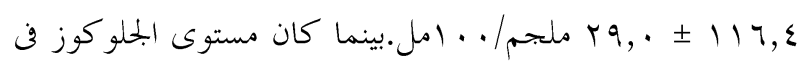

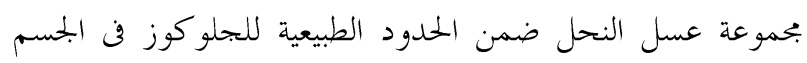

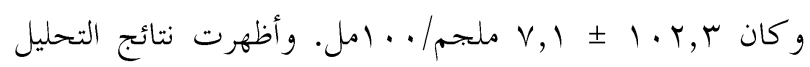
الإحصائي وجود فروق معنوية بين البمموعة الضابطة وبين المجموعات التجريبة الثلاث(جدول ورون ه). وتتفق هذه النتائج مع (2002) Fararh, et al الذي أشار أن

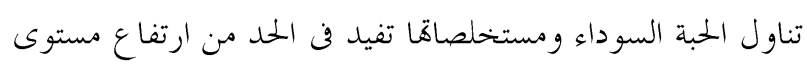

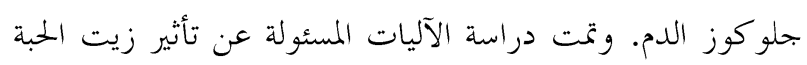

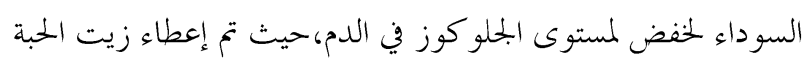
السوداء بجرعة ( . . ع ملجم/كجم من وزن الجسم لمدة 7 أسابيع)

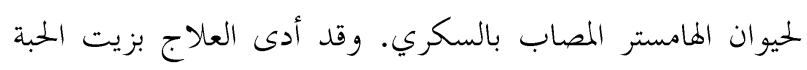

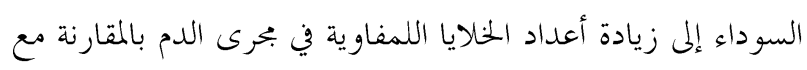

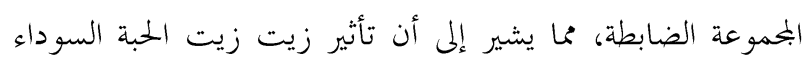

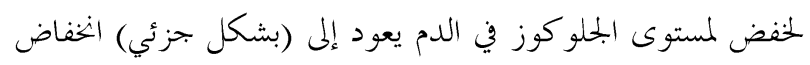

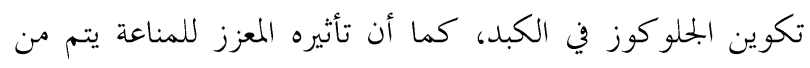


العلاج الكيميائي القياسي والعلاج الإشعاعي والهرمونى في مرضى

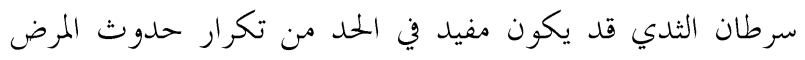

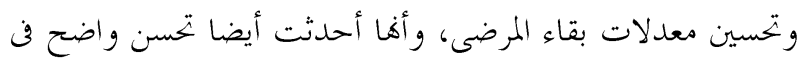
مستويات جميع المقاييس الكيموحيوية بالمسبم. ويستنتج من هذه الدراسة أهمية اللجوء إلى العلاج التكميلي

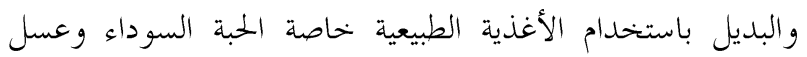

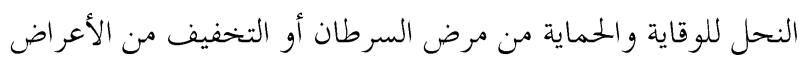

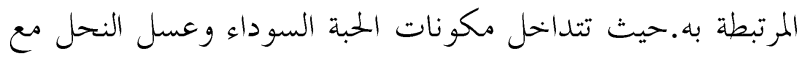

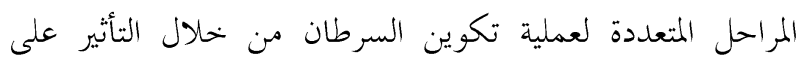

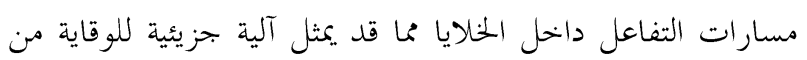
السرطان. ويتميز عسل النحل بخواصه المضادة للالتهاب، المضادة للأكسدة، المضادة لنمو الأورام، المحفزة لموت الخحلايا المبرمج، وتأثيره

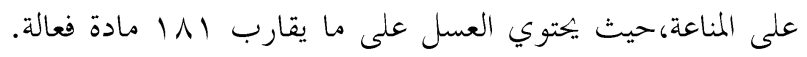
أما الحبة السوداء فتأثيرها يرجع إلى قدرها على تلى تدمير الخلايا

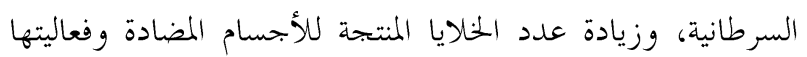
المضادة لنمو الأورام.

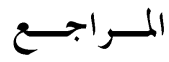

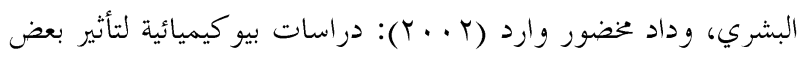

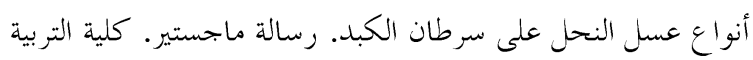
للبنات بجدة- الأقسام العلمية. المملكة العر بية السعودية.

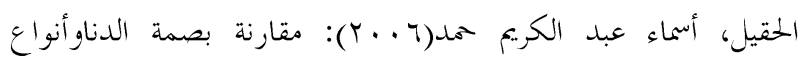

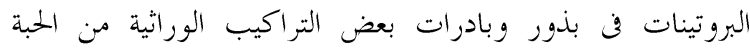
السوداء Nigella Sativa .رسالة دكتوراه،جامعة الملك سعود. المملكة العر بية السعودية.

محمد، رجاء حسين- البسطاويسي، آمال محمد- عبد المنعم، محمد جميل؛؛ذكرى، خالد ذكرى- الخضار حسين عبد الرحمن- إلباسمي،

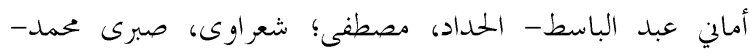

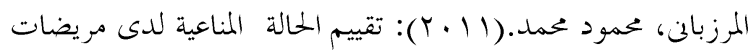

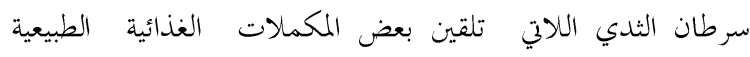

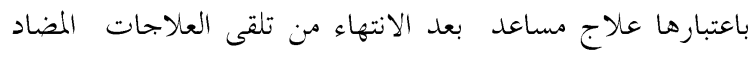
للسرطان. المؤتمر العالمي العاشر للإعجاز العلمي في القرآن والسنة.

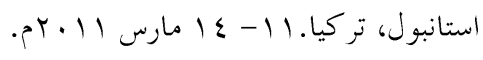

التحليل الإحصائي وجود فروق معنوية(مستوى دلالة أقل ( •، ·) بين المحموعة الضابطة وبين البحموعات التجريبية الثلاث اللاتي

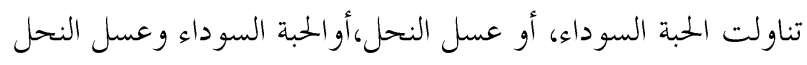

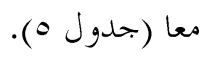
لم يلاحظ وجود فروق معنوية بين مستوى البليروبين بين المجموعة الضابطةوبين البمموعات التجريبية الثلاث اللاتي تناولت

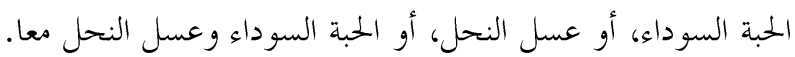

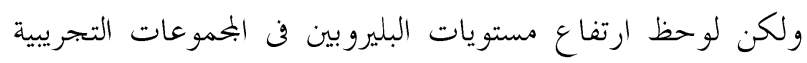

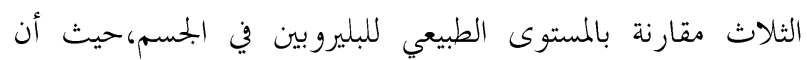

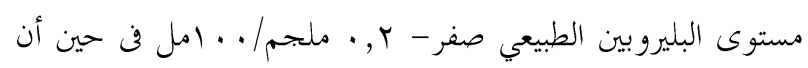

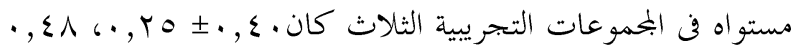

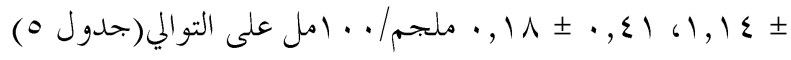

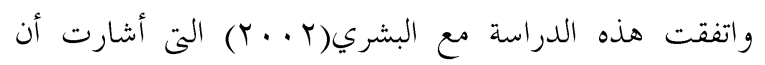

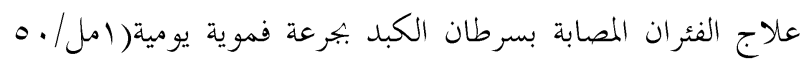

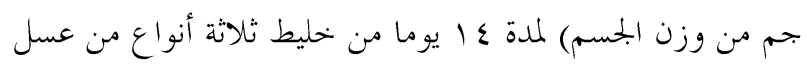

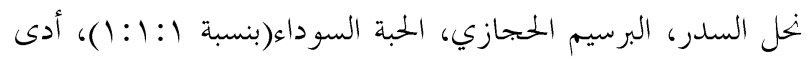

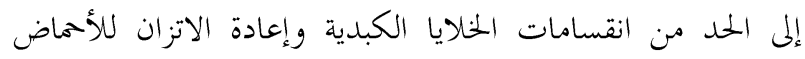
النووية والبروتين الكلى وبالتالي الحد من تطور مرض السرطان.

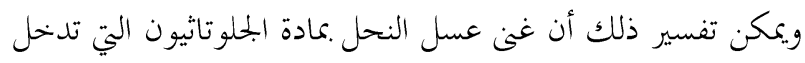

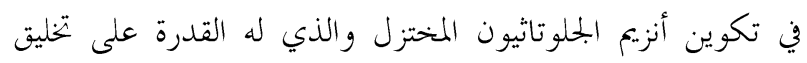

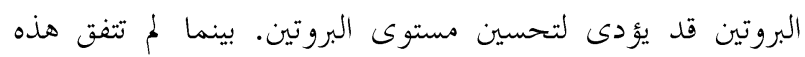

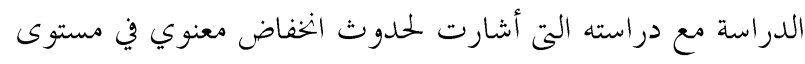
البليروبين في سيرم دم الفئران المصابة وهذا عكس نتائجنا التى لتصني أشارت لحدوث ارتفاع في مستويات البليروبين في البمموعات التجريبية الثلاث مقارنة بالمستوى الطبيعي للبليروبين في الجسم. وتتفق هذه النتائج مع دراسة(2005) Garofolo, et al التى

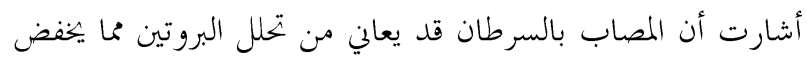

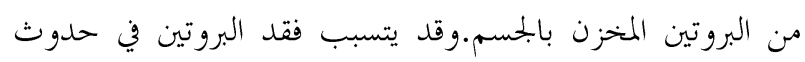

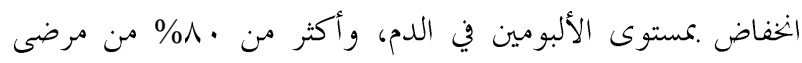
السرطان يقل مستوى بروتين الألبومين في الدم لديهم. وتتفق هذه

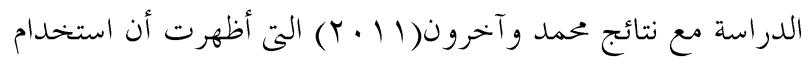

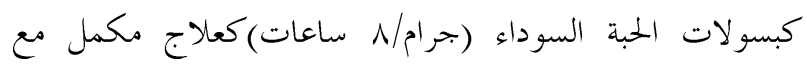


Edris, A. (2009): Anti-Cancer Properties of Nigella spp. Essential Oils and their Major Constituents, Thymoquinone and $\beta$-Elemene. Current Clinical Pharmacology. 4(43):46 - 43.

Fararh, K.; Atoji, Y. ; Shimizu, Y. and Takewaki, T. (2002): Isulinotropic properties of Nigella sativa oil in Streptozotocin plus Nicotinamide diabetic hamster. Res. Vet. Sci. 73(3): 279-282.

Garofolo, A.; Lopez, F.and Petrilli, A. (2005):High prevalence of malnutrition among patients with solid nonhematological tumors as found by using skin fold and circumference measurements. Sao Paulo Med J.123:277281.

Gianni, L.; Cole, F.; Panzini, I.; Snyder, R.; Holmberg, B.; Byrne, M.; Crivellari, D. and Colleoni, M.(2008): Anemia during adjuvant non-taxane chemotherapy for early breast cancer: Incidence and risk factors from two trials of the international breast cancer study group. Support Care Cancer. 16:67-74.

Gold, E.; Pierce, J.; Natarajan, L.; Stefanick, M.; Laughlin, G.; Caan, B.; Flatt, S.; Emond, J.; Saquib, N. and Madlensky, L.(2009: Dietary pattern influences breast cancer prognosis in women without hot flashes: the women's healthy eating and living trial. J Clin Oncol. 27: 352-359.

Ibrahim, E.; Zeeneldin, A. and Bin Sadiq, B. (2008):The present and the future of breast cancer burden in the Kingdom of Saudi Arabia. Journal of Clinical Oncology, 2008 ASCO Annual Meeting Proceedings. 26: 15S.

Islam, S. ; Begum, P. ; Ahsan, T. ; Hugue, S. and Ahsan, M. (2010): Immunosuppressive and cytotoxic properties of Nigella sativa. Phytother Res. 18(5):395-358.

Jan, N. ; Sundquist, H. and Bruning, N.(2007): Coping with Cancer and Chemotherapy, compassionate advice and authoritative information from a chemotherapy survivor, penguim .com. Available at: http//:books. Google. Com/ books?id=6-chemotherapy+side effects.

Kapoor, S. (2009): Emerging clinical and therapeutic applications of Nigella sativa in gastroenterology. World J Gastroenterol. 15(17): 2170-2171.

Khalil, N.; Alaa El- Din, S. ; Salem, M. ; Seif El-Din, A. and Arafat, W. (2010): The Effect of Combining Herbal Therapy with Conventional Chemotherapy on the Incidence of Chemotherapy Side Effects in 2nd Stage Breast Cancer Patients. Journal of American Science 6(11): 784-801.

Lewis, M. ; Bain, B. and Bates, I.(2006):Dacie and Lewis Practical Haematology. Tenth Edition. Churchill Livingstone Elsevier.

Leyland-Jones, B.; Semiglazov, V.; Pawlicki, M.; Pienkowski, T. Tjulandin, S.;Manikhas, G.; Makhson, A.and Roth, A.(2005): Maintaining normal hemoglobin levels with epoetin alfa in mainly nonanemic patients with metastatic breast cancer receiving first-line chemotherapy: A survival study. J Clin Oncol.23:5960-5972.

$$
\begin{aligned}
& \text { المدني، خالد( ع . · †).تقييم الحالة الغذائية. الطبعة الثالثة. مطبعة المدلي. } \\
& \text { جدة. } \\
& \text { المركز العربي للتغذية (V . . r). البرنامج العربي لتحليل الأغذية.ميزان } \\
& \text { الصحة للتغذية العلاجية.الإصدار الأول. ترخيص وزارة الثقافة }
\end{aligned}
$$

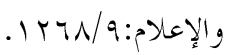

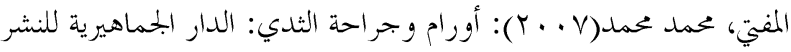

$$
\begin{aligned}
& \text { والتوزيع والإعلان، دار الكتب الوطنية، الطبعة الأولى، بنغازي، } \\
& \text { ص: }
\end{aligned}
$$

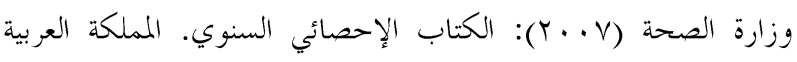

$$
\begin{aligned}
& \text { السعودية. }
\end{aligned}
$$

Ait Mbarek, L. ; Ait Mouse, H. ; Elabbadi, N. ; Bensalah, M. ; Gamouh, A. ; Aboufatima, R. ; Benharref, A. ; Chait, A. ; Kamal, M. ; Dalal, A. and Zyad, A. (2007): Anti-tumor properties of black seed (Nigella sativa L.) extracts. Braz. J. Med. Biol. Res. 40(6) 839-847.

Alharbi, A. (2008): The effect of chemotherapy on nutritional status of breast cancer patients. Master's degree in the department of community health sciences at the college of applied medical sciences King Saud University.

10-American Cancer Society (ACS), and National Comprehensive Cancer Network (NCCN) (2008): Brest Cancer. Available http://www.nccn.org/patients/patientgls/english/breast.asp.

Bartels, H. (1972): Determination of serum Creatinine. Clin. Chim. Acta 37:193.

Boehm, U.; Lebrecht, A.; Schmidt, M.; Siggelkow, W.; Lindner, C. and Litz, A. (2007): Prognostic impact of hemoglobin levels in breast cancer. Anticancer Res.27:1223-1226.

Brown, J. ;Byers, T.; Doyle, C.; Courneya, K.; Wahnefried, W.; Kushi, L.; Mctiernan, A.; Rock, C.; Aziz, N.; Bloch, A.; Eldridge, B. and Hamilton, K.(2003):Nutrition and physical activity during and after cancer treatment: An American cancer society guide for informed choices. CA Cancer J Clin.53:268-291.

Campbell, K.; Lane, K.; Martin, A.; Gelmon, K.and McKenzie, D.(2007): Resting energy expenditure and body mass changes in women during adjuvant chemotherapy for breast cancer. Cancer Nursing. 30:95100.

Cancer Compass/ Breast Cancer Information/ Side Effects (2008). www. Cancer Compass.com.

Debasis, B. and Preuss, H.(2005): Phytopharmaceuticals in Cancer Chemoprevention. CRC Press. Boca Raton London New York Washington, D.C. 


$$
\text { حسن عبد الرعوف الهندي وأخرون.،: تأثير تناول الحبة السوداءوعسل النحل على الحالة الصحية للمصابات بسرطان الثدي }
$$

Tavani1, A.; Giordano1, L. ; Gallus1, S. ; Talamini, R. ; Franceschi, S. ;Giacosa, A. and Montella, M. (2006): Consumption of sweet foods and breast cancer risk in Italy. Annals of Oncology 17: 341-345.

Thiébaut, A.; Kipnis, V. ; Chang, S.; Subar, A.; Thompson, F. and Rosenberg, P.(2007): Dietary fat and postmenopausal invasive breast cancer in the National Institutes of HealthAARP Diet and Health

Tian, J.; Chen, Z.and Hang, L. (2007): Effects of nutritional and psychological status in gastrointestinal cancer patients on tolerance of treatment. World J Gastroenterol.13:41364140 .

Trinder, P.(1969): Cited from chmory enzymatic glucose reagent set (colorimetric). Ann. Clin. Biochem. 6, 24.

Weichselbaum, T. (1964): Amer. J. Clin. Path, 16:40.

World Health Organization news release. (WHO): 2003.http://www. who.int/ mediacentre/ news/ release s/2003/pr27/en/.
Mabrouk, G.; Moselhy, S. ; Zohny, S. ; Ali, E. ; Helal, T. ; Amin, A. and Khalifa, A. (2002):Inhibition of methylnitrosourea (MNU) induced oxidative stress and carcinogenesis by orally administered bee honey and Nigella grains in Sprague Dawely rats. J. Exp. Clin. Cancer Res. 21(3):341-346.

Nagi, M.; Hosny, C. and Maher, G.(2008): Pharmacological and Toxicological Properties of Nigella Sativa, Journal of Pakistan Medical Association.41: 185-187.

Neumann, U. and Ziegenhorn, J. (1977). Scand. J. Clin. Lab. Invest. 37: Supplement 147, Abstract 97.

Parviainen, M. (1997): A modification of the diazo coupling method (Malloy-Evelyn) for the determination of serum total bilirubin. Scand J. Clin. Lab. Invest. 57:275-280.

SAS "Statistical Analysis System" (2000): SAS user guide: Statistics Version 8 edition, Inc., Carry, NC.

\title{
SUMMARY \\ Effect of Intake Black Seeds and Bee Honey on Health Status of Breast Cancer Patients
}

\author{
Hassan Abdel Raouf El- Hendy, Mohamed Sherif Askar, Susan Abdel Rahman Abo shal
}

This study aimed to determine the effect of black seed and honey on the status of women with breast cancer. This study was conducted at the Department of Oncology in Al-Noor Specialist Hospital and King Abdullah Medical City, Holy Makkah. The sample consisted of fifty-four patients, aged more than 18 years to 70 years. The sample was divided into four groups. All of these groups continued the treatment of chemotherapy and the first group (14 patients) was considered as the control group: the second group (11 patients) was given a daily intake of black seed (0.2 $\mathrm{g} / \mathrm{kg}$ body weight); the third group (14 patients) was given a daily intake of honey (60 grams); while the fourth group (15 patients) was the group that was given both the black seed and honey similar to the second and third intakes for a period of 5 days a week. Also, intakes of black seed, honey, black seed and honey together continued for two weeks after the end of chemotherapy.

The data was collected by a questionnaire which included several parameters that comprising personal data, health information, assessment of dietary intake, and biochemical analyses. The study concluded the importance of using of complementary and alternative treatment by using natural foods especially black seed and honey for the prevention and protection from cancer or alleviation of side effects associated with various cancer treatments. 